\title{
APLIKASI SILIKA MCM-41 SEBAGAI MATERIAL BERPORI DALAM ADSORPSI IBUPROFEN
}

\section{APPLICATION OF SILICA MCM-41 AS POROUS MATERIAL TO IBUPROFEN ADSORPTION}

\author{
Mustofa Ahda \\ Fakultas Farmasi Universitas Ahmad Dahlan \\ Email: mustofa_ahda@yahoo.com
}

\begin{abstract}
ABSTRAK
Telah dilakukan kajian terhadap proses pemanfaatan MCM-41 sebagai padatan pendukung dalam transfer ibuprofen. MCM-41 disintesis menggunakan metode hidrotermal. Aplikasi MCM-41 sebagai padatan pendukung dilakukan dengan mengamati perubahan karakter MCM-41 baik struktur kristal MCM-41 dan kemampuan adsorpsinya terhadap ibuprofen. Hasil karakterisasi dengan difraksi sinar X terdeteksi $2 \Theta: 22,62$ dan 23,10. Hal ini menunjukkan bahwa kemampuan adsorpsi MCM-41 terhadap ibuprofen terdeteksi dengan penghilangan pelarut pada temperatur kamar. Hal ini juga dibuktikan dengan data kemampuan MCM41 dalam mengadsorpsi ibuprofen mengalami kenaikan dengan bertambahnya konsentrasi ibuprofen.
\end{abstract}

Kata kunci: MCM-41, ibuprofen, adsorpsi

\begin{abstract}
The Study of MCM-41 as a solid support in the transfer of ibuprofen has been done. MCM-41 was synthesized using a hydrothermal method. Application of MCM-41 as a solid support is observed in term of the changes of the MCM-41 structure such as crystal structure and adsorption ability to ibuprofen. The results of $X$-ray diffraction characterization detected 2O: 22.62 and 23.10, respectively. This results show that the adsorption activity of MCM-41 to ibuprofen was detected by removal of solvent at room temperature. This is also evidenced in the data capabilities of MCM-41 to ibuprofen adsorption increased with increasing concentrations of ibuprofen.
\end{abstract}

Keywords: MCM-41, ibuprofen, adsorption 


\section{PENDAHULUAN}

Pemanfaatan nanomaterial merupakan salah satu aplikasi dalam bidang farmasi sebagai pengontrol transfer obat. Penggunaan nanomaterial dalam transfer obat dikarenakan nanomaterial memiliki banyak kelebihan. Salah satu jenis nanomaterial yang banyak dikaji ialah MCM-41. MCM-41 merupakan material yang pertama diteliti oleh mobil corporation. Material ini memiliki struktur heksagonal dan mirip seperti sarang lebah (Kim, et al., 1995). MCM-41 memiliki ukuran pori dalam kisaran 2- $50 \mathrm{~nm}$ sehingga disebut dengan material mesopori. Ukuran pori heksagonal pada MCM-41 ini menjadikan material tersebut dapat melakukan proses adsorpsi terhadap suatu obat. Kelebihan MCM-41 yang lainnya ialah luas permukaan yang besar. Ahda et al. (2011) berhasil mensintesis silika MCM-41 secara hidrotermal dengan luas permukaan mencapai $1000 \mathrm{~m}^{2} / \mathrm{g}$.

Keunggulan ini dijadikan dasar utama pengembangan MCM41 sebagai padatan pendukung dalam transfer obat. Regi (2012) menyatakan bahwa material silika mesopori sangat potensial dalam nanomedicine. Oleh karena itu pemanfaatan luas permukaan dan ukuran pori yang besar pada MCM41 diharapkan obat dapat masuk dan terdispersi dalam pori dan permukaan MCM-41, hal ini menyebabkan luas situs aktif obat meningkat sehingga mampu meningkatkan aktifitas obat.

Hal ini sesuai dengan yang dinyatakan Regi dan Balas (2008) bahwa aplikasi silika material dalam kedokteran dan bioteknologi dipengaruhi oleh struktur, komposisi kimia pada karakter dan sifat akhir materialnya. Pemanfataan MCM-41 dalam dunia kedokteran dikarenakan nanopartikel MCM-41 memiliki sitotoksik yang rendah (Patil, et al., 2011). Naik dan Ghosh (2009) menyatakan silika dan alumina mesopori merupakan material dasar yang dapat digunakan sebagai katalis, adsorben, dan padatan pendukung dalam enkapsulasi. Hal ini karena MCM-41 dapat mengatur lepasnya obat secara bertahap sehingga mengurangi terjadinya over dosis.

Dalam penelitian ini, obat yang digunakan sebagai objek ialah 
ibuprofen. Ibuprofen merupakan jenis obat anti-inflamasi nonsteroid yang sering digunakan. Ibuprofen memiliki waktu paruh biologis yang pendek yaitu lebih kurang dua jam sehingga perlu digunakan berulangkali dalam sehari. Dalam bentuk tablet, ibuprofen pada umumnya diberikan dengan dosis $200 \mathrm{mg}$ sampai $800 \mathrm{mg}$, tiga sampai empat kali sehari. Sistem pelepasan terkendali merupakan metode yang dapat digunakan untuk mengurangi efek samping terhadap sistem pencernaan dan mengatasi waktu eliminasi yang cepat, Salah satu metode yang dapat dilakukan adalah dengan cara enkapsulasi obat dalam ukuran kecil. Proses enkapsulasi ibuprofen pada matriks silika mesopori telah dilakukan oleh Anderson, et al. (2004) yang melaporkan bahwa serapan ibuprofen dengan heksan model adsorpsinya mengikuti model Langmuir. Proses enkapsulasi ibuprofen dalam MCM41 dapat digunakan untuk obat yang digunakan oral dan memiliki banyak

kelemahan seperti waktu eliminasi yang cepat.

Penelitian ini dilakukan proses enkapsulasi ibuprofen pada
MCM-41 dalam media aquades. Untuk mengetahui keberhasilan proses sintesis dan proses enkapsulasi obat pada MCM-41 maka dilakukan karakterisasi dengan XRD, spektroskopi FTIR, dan uji kemampuan adsorpsi terhadap ibuprofen.

\section{METODE PENELITIAN}

Alat-alat yang digunakan pada penelitian ini adalah: alat-alat gelas volumetrik, spektrofotometer IR (Shimadzu FTIR 8201 Prestige 21), XRD (Shimadzu XRD 6000) dan timbangan analitik. Bahan-bahan yang digunakan dalam penelitian ini meliputi: natrium silikat $\mathrm{Na}_{2} \mathrm{SiO}_{3} .9 \mathrm{H}_{2} \mathrm{O}$ (27\% SiO2, Merck), setiltrimetilammmonium bromida (CTAB, Merck), $\quad \mathrm{CH}_{3} \mathrm{COOH}$ (Merck), aquades, dan ibuprofen.

Jalannya Penelitian

Sintesis MCM-41

MCM-41 disintesis berdasarkan penelitian Ahda, et al. (2011) dengan komposisi molar campuran $1 \mathrm{SiO}_{2}: 0,25 \mathrm{CTAB}: \mathrm{O}, 29$ $\mathrm{Na}_{2} \mathrm{O}$ : $50 \mathrm{H}_{2} \mathrm{O}$. Sebanyak 2,277 g CTAB dilarutkan dalam 18,882 $\mathrm{g}$ akuades selama 30 menit pada temperatur $60^{\circ} \mathrm{C}$ dan didinginkan. 
Setelah itu ditambahkan 7,512 g $\mathrm{Na}_{2} \mathrm{SiO}_{3}$ tetes demi tetes dan dilakukan pemanasan pada temperatur $60^{\circ} \mathrm{C}$ selama 1 jam dengan diaduk sampai homogen dan didinginkan kembali. Kemudian $\mathrm{pH}$ campuran diatur pada $\mathrm{pH} 10$ dengan menambahkan asam asetat $1 \mathrm{M}$ dan dilakukan pengadukan selama 2 jam. Campuran dimasukkan dalam autoklaf dan dipanaskan pada temperatur $100^{\circ} \mathrm{C}$, dengan variasi waktu hidrotermalnya selama 24 jam. $\mathrm{pH}$ akhir campuran menunjukkan kenaikan sampai $\mathrm{pH}$ 11. Campuran disaring dan dicuci dengan akuades sampai netral kemudian dikeringkan dalam oven pada temperatur $100^{\circ} \mathrm{C}$ semalam.

Kalsinasi dan karakterisasi MCM-41 MCM-41 yang disintesis kemudian dikalsinasi pada temperatur $550^{\circ} \mathrm{C}$ selama 5 jam dengan laju pemanasan $2^{\circ} \mathrm{C} /$ menit. hasil sintesis dikarakterisasi dengan difraksi sinar-X dan spektrofotometri FTIR.

\section{Adsorpsi Ibuprofen}

Proses adsorpsi ibuprofen dilakukan dengan membuat larutan ibuprofen dengan konsentrasi $1 \mathrm{mg} / \mathrm{mL}, 2 \mathrm{mg} / \mathrm{mL}, 3 \mathrm{mg} / \mathrm{mL}, 4$ $\mathrm{mg} / \mathrm{mL}$ dalam isopropanol yang dicampurkan dengan 0,1 g MCM-41 dan diaduk selama 30 menit pada suhu kamar. Kemudian untuk mengetahui ibuprofen yang masuk dikeringkan pada suhu $100{ }^{0} \mathrm{C}$ kemudian dikarakterisasi dengan XRD dan spektrum FTIR.

\section{HASIL DAN PEMBAHASAN}

Karakterisasi Nanopartikel MCM-41 dengan XRD

Penelitian ini melakukan sistesis MCM-41 secara hidrotermal dengan lama waktu 24 jam. Hasil sintesis MCM-41 pada penelitian ini memiliki kristalinitas yang tinggi dan tingkat keteraturan yang baik. Kristalinitas MCM-41 ditandai dengan munculnya puncak utama pada bidang [100] didaerah $2 \Theta$ sekitar $2,08^{\circ}$ dengan intensitas yang tinggi dan keteraturan struktur heksagonal dari kristalin MCM-41 dan didukung dengan munculnya puncak-puncak lain sekitar $2 \Theta$ pada daerah $4-5^{\circ}$ yang menunjukkan indeks bidang [110] dan [200] (Gambar 1).

Hasil penelitian ini menunjukkan bahwa MCM-41 memiliki kristalinitas yang baik dibandingkan dengan setelah 
masuknnya ibuprofen dalam MCM41.

Hal ini dikarenakan adanya pergeseran struktur heksagonal MCM-41 sehingga menurunkan kristalinitas. Hal ini juga didukung dengan adanya perubahan unit sel $\left(\mathrm{a}_{0}\right) \quad \mathrm{MCM}-41$ yang sedikit mengalami peningkatan (Tabel 1).
Gao, et al. (2012), menyatakan penurunan pada bidang [100] didaerah $2 \Theta$ sekitar $2,08^{\circ}$ yang menandakan adanya proses adsorpsi ibuprofen.

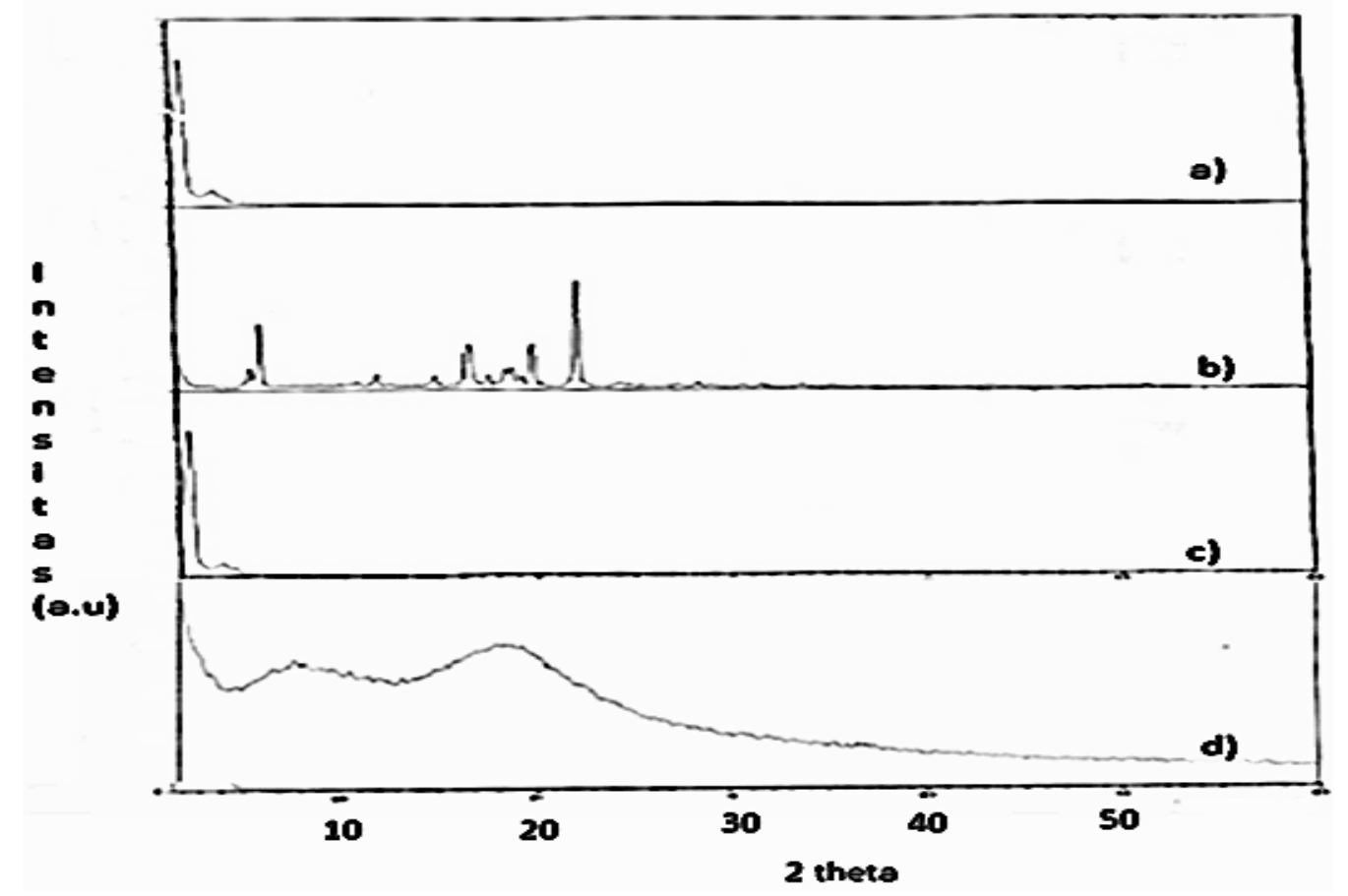

Gambar 1. Pola difraksi sinar-X, a) MCM-41 sebelum adsorpsi, b) Ibuprofen, c) MCM-41 setelah adsorpsi Ibuprofen (Pengeringan $110{ }^{\circ} \mathrm{C}$ ), d) MCM41 setelah adsorpsi Ibuprofen (pengeringan pada suhu kamar)

Hasil Difraksi sinar-X tidak muncul. Ada dugaan bahwa ibuprofen (Gambar 1) menunjukkan adanya karakteristik puncak yang ibuprofen mengalami peleburan saat pengeringan MCM-41-ibuprofen khas yaitu pada 2Ө: 22,21 (100\%); dengan suhu $110^{\circ} \mathrm{C}$. Hal ini karena $5,97 \quad(54 \%) ; 16,20 \quad(37 \%) ; 19,97$ titik lebur ibuprofen sekitar 75 (36\%) dan puncak lainnya yang kecil-kecil. Akan tetapi setelah proses masuknya ibuprofen pada MCM-41 puncak-puncak tersebut $78^{\circ} \mathrm{C}$. Dugaan tersebut mendorong dilakukan pengeringan MCM-41 + ibuprofen pada temperatur kamar. Akan tetapi hasil karakteristik XRD 
menunjukkan ada perubahan struktur kristal MCM-41 menjadi struktur amorf. Hal ini merupakan indikasi bahwa ibuprofen tidak masuk pada pori-pori MCM-41 akan tetapi menutupi rongga pori MCM-41 sehingga struktur kristal MCM-41 menjadi amorf.

Karakterisasi Nanopartikel MCM-41 dengan Spektroskopi IR

$$
\text { Karakterisasi nanopartikel }
$$

dengan spektroskopi inframerah (IR) ditunjukkan untuk mendeteksi perubahan vibrasi gugus yang terjadi. Hasil spektrum IR memperlihatkan bahwa sintesis MCM-41 tidak menyebabkan perubahan bilangan gelombang pada hasil spektra inframerah. Serapan lebar yang muncul di daerah sekitar 3400-3500 $\mathrm{cm}^{-1}$ yang menandakan vibrasi gugus hidroksi (-OH) yang mungkin berasal dari vibrasi gugus silanol dan serapan pada daerah sekitar $1636 \mathrm{~cm}^{-}$ 1 berasal dari vibrasi molekul air (Gambar 2).

Serapan pada bilangan gelombang $1240 \mathrm{~cm}^{-1}$ dan $1083 \mathrm{~cm}^{-1}$ merupakan vibrasi uluran asimetrik Si-O-Si dan serapan pada bilangan gelombang $795 \mathrm{~cm}^{-1}$ merupakan vibrasi uluran simetrik $\mathrm{T}-\mathrm{O}-\mathrm{T}(\mathrm{T}=\mathrm{Si}$ atau $\mathrm{Al}$ ) dan serapan khas sekitar 463 $\mathrm{cm}^{-1}$ merupakan bentuk vibrasi tekuk $\mathrm{TO}_{4}$

Oleh karena itu, dapat dikatakan bahwa proses adsorpsi ibuprofen pada MCM-41 tidak mempengaruhi vibrasi molekul atom-atom penyusun kerangka MCM-41. Tidak adanya vibrasi gugus-gugus khas dari ibuprofen seperti vibrasi benzene yang akan melakukan muncul pada

Tabel I. Karakter MCM-41 sebelum dan sesudah adsorpsi

\begin{tabular}{|c|c|c|}
\hline \multirow{2}{*}{ Material } & \multicolumn{2}{|c|}{ Parameter } \\
\hline & $\begin{array}{c}\text { Kristalinitas Relatif } \\
(\%)\end{array}$ & $\begin{array}{c}\text { Unit Sel, } \mathbf{a}_{0} \\
(\AA)\end{array}$ \\
\hline MCM-41 & 100 & 48,8 \\
\hline $\begin{array}{l}\text { MCM-41 + Ibuprofen } \\
\left(\mathrm{T}: 110^{0} \mathrm{C}\right)\end{array}$ & 96 & 49.00 \\
\hline $\begin{array}{c}\text { MCM-41 + Ibuprofen (Room } \\
\text { Temperature) }\end{array}$ & 7,5 & 41,48 \\
\hline
\end{tabular}


bilangan gelombang sekitar 1500 dan $1600 \mathrm{~cm}^{-1}$, vibrasi alkena pada bilangan $3100 \mathrm{~cm}^{-1}$ dan vibrasi alkana pada bilangan $2800-2900 \mathrm{~cm}^{-}$

1 yang menunjukkan adanya vibrasi ulur $\mathrm{C}-\mathrm{H}$ dan didukung dengan muncul serapan pada bilangan gelombang $1489 \quad \mathrm{~cm}^{-1}$ yang menunjukkan vibrasi tekuk $\mathrm{C}-\mathrm{H}$ gugus metilen $\left(-\mathrm{CH}_{2}-\right)$. Karakter vibrasi gugus ibuprofen tidak terdeteksi setelah proses adsorpsi. Hal ini menandakan bahwa memang terindikasi bahwa ibuprofen mungkin tidak terdapat pada padatan nanopartikel MCM-41 yang disebabkan pengeringan material $110^{0} \mathrm{C}$.

Aplikasi MCM-41 untuk Adsorpsi Ibuprofen

Penelitian ini menggunakan MCM-41 sebagai nanopartikel yang berfungsi untuk mengadsorpsi ibuprofen. Kemampuan adsorpsi MCM-41 dapat dijadikan dasar proses enkapsulasi suatu obat pada padatan nanopartikel. Hal ini karena perkembangan modifikasi nanopartikel sebagai padatan pendukung sebagai sistem transfer obat terus berkembang baik dari organik maupun anorganik.

$$
\text { Senyawa ibuprofen }
$$

menghasilkan serapan maksimum pada panjang gelombang maksimal 263,8 nm. Oleh karena itu proses immobilisasi ibuprofen juga akan dilakukan dalam kondisi netral sesuai dengan data panjang gelombang maksimal yakni 263,8 nm. Hasil penentuan panjang gelombang ibuprofen 263,8 nm dalam pelarut isopropanol kemudian 

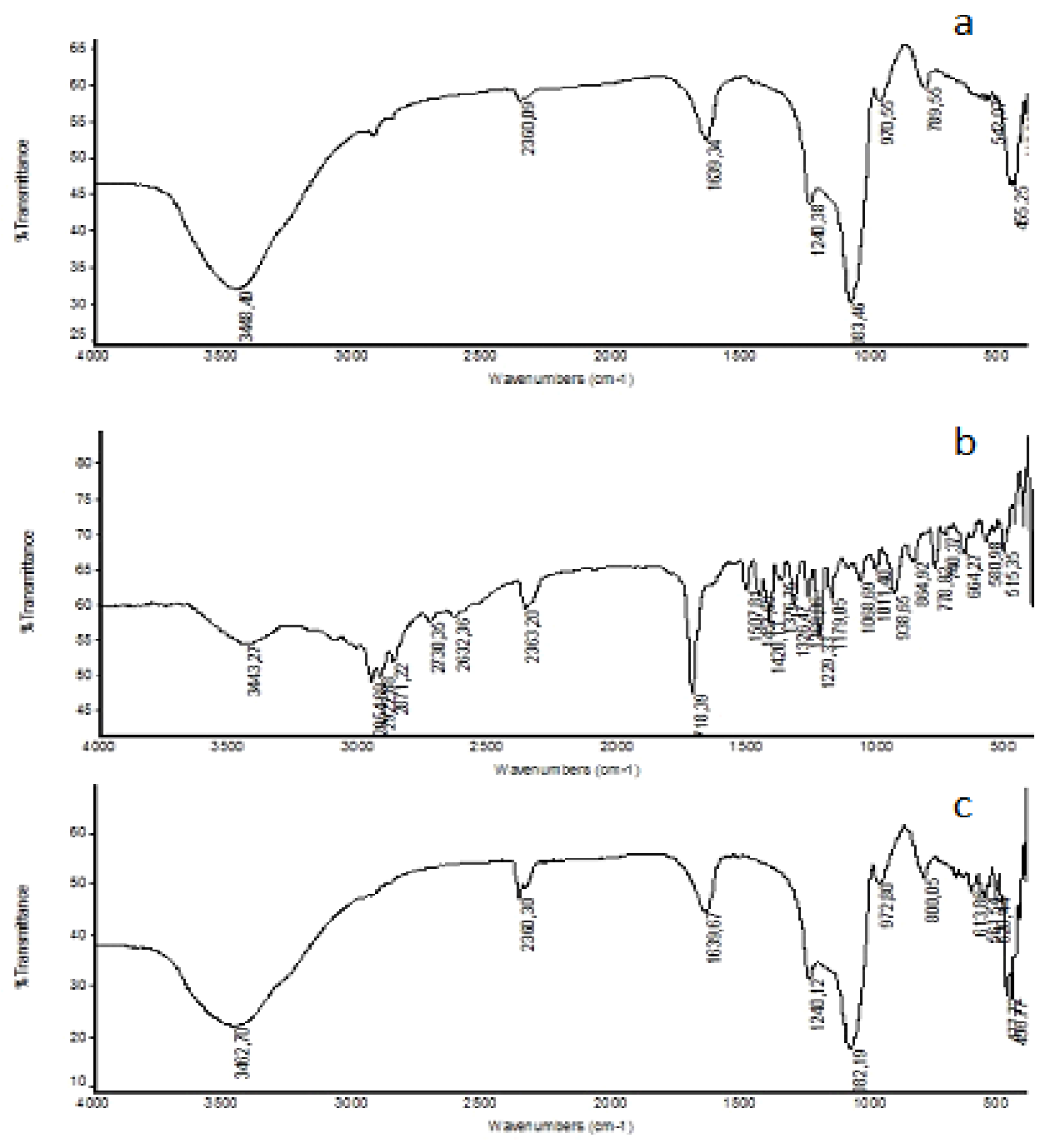

Gambar 2. Spektra inframerah: a) MCM-41 sebelum adsorpsi, b) Ibuprofen, c) MCM-41 setelah adsorpsi Ibuprofen

menjadi landasan panjang $\mathrm{R}^{2}=0,999$. Hasil ini gelombang maksimum dalam mengindikasikan bahwa konsentrasi membuat kurva kalibrasi dan dengan absorbansi memiliki korelasi penentuan aktifitas adsorpsi MCMyang baik. Persamaan regresi linier 41. Kurva kalibrasi hubungan antara mengikuti persamaan $\mathrm{y}=1,434 \mathrm{x}-$ pengaruh konsentrasi ibuprofen 0,155 . Persamaan tersebut memiliki terhadap absorbansinya memiliki slope sebesar 1,434 dan intersep linieritas yang baik dengan harga sebesar 0,155 (Gambar 3). 


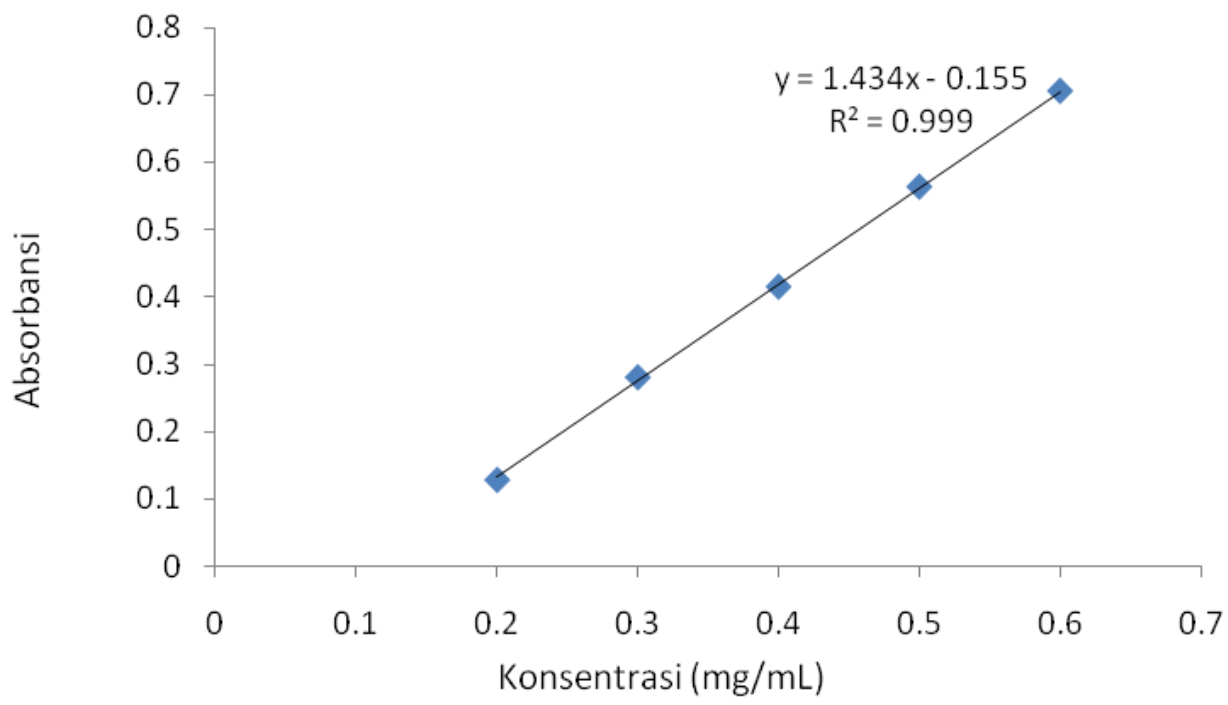

Gambar 3. Kurva Baku Ibuprofen yang menyatakan hubungan antara konsentrasi $0,2-0,6 \mathrm{mg} / \mathrm{mL}$ dalam $\mathrm{NaOH} 0,1 \mathrm{~N}$ dengan nilai absorbansinya

Penentuan Aktifitas adsorpsi MCM- ditingkatkannya konsentrasi larutan 41 terhadap Ibuprofen

Persamaan hasil kurva baku ibuprofen meningkat pula ibuprofen yang diperoleh digunakan kemampuan adsorpsinya. Aktifitas sebagai daerah kerja pada penentuan MCM-41 dilakukan dalam waktu 30 aktifitas adsorpsi MCM-41. Hasil menit dengan konsentrasi ibuprofen aktifitas MCM-41 memiliki kemampuan adsorpsi terhadap ibuprofen, bahkan dengan

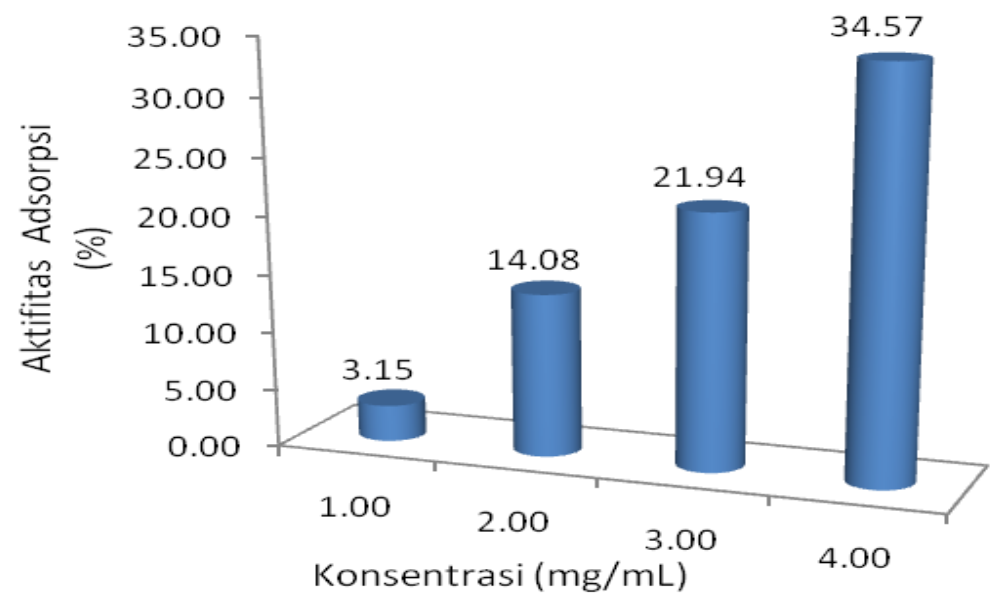

Gambar 4. Kemampuan MCM-41 dalam mengadsorpsi Ibuprofen 
Hasil aktifitas adsorpsi MCM-41 terhadap ibuprofen masih mengalami kenaikan yang signifikan. Hal ini mengindikasikan bahwa kemampuan adsorpsi MCM-41 terhadap ibuprofen belum mencapai kesetimbangan. Kesetimbangan dapat terjadi jika permukaan silanol (Si-OH) dan rongga heksagonal MCM-41 telah mengadsorpsi ibuprofen menyeluruh secara monolayer. Pembentukan adsorpsi monolayer pada permukaan MCM41 tersebut memungkinkan terjadinya pembentukan multilayer akan tetapi peningkatan adsorpsinya tidak signifikan bahkan aktifitasnya dapat mengalami proses desorpsi sehingga aktifitas adsorpsinya menurun.

\section{KESIMPULAN}

Material MCM-41 memiliki kemampuan adsorpsi terhadap ibuprofen hal ini diindikasi dengan adanya penutupan pori pada MCM41 sehingga membentuk struktur amorf dan adanya daya adsorpsi $34,57 \%$ pada konsentrasi ibuprofen 4 $\mathrm{mg} / \mathrm{mL}$.

\section{DAFTAR PUSTAKA}

Ahda, M., Sutarno., Kunarti, E.S., 2011, Pengaruh Penambahan Aluminat dan TMAOH terhadap Stabilitas Material Mesopori MCM-41, Seminar Nasional Kimia VI.

Anderson, J., Rosenholm, J., Areva, S., Linden, M., Influence of Material Characteristics on Ibuprofen Drug Loading and Realese Profile from Ordered Micro and Mesoporous Silica Matrices, Chem. Mater, 16: 4160-4167.

Araujo, R.S., Costa, F.S., Maia, D.A.S., Sant'Ana, H.B., and Cavalcante Jr, C.L., 2007, Synthesis and Characterization of Al-MCM-41 and Ti-MCM41 Materials: Application to Oxidation of Anthracene, Braz. J. Chem. Eng., 24 (01) : $135-141$

Gao, L., Sun, J., Zhang, L., Wang, J., Ren B., 2012, Influence of different structured channels of mesoporous silicate on the controlled ibuprofen delivery, Materials Chemistry and Physics, 135: 786-797.

Kim, J.M., Kwak, J.H., Jun, S., and Ryoo, R., 1995, Ion Exchange and Thermal Stability of MCM-41, J. Phys. Chem., 99 (45): 16742-16747.

Naik, B., and Ghosh, N.N., 2009, an A Review on Chemical Methodologies for Preparation of Mesoporous Silica and Alumina Based Materials, Recent Patents on Nanotechnology, 3(3): 213224.

Patil, A., Chirmade, U.N., Trivedi, V., Lamprou, D.A., Urquhart, A., Douroumis, D., 2011, 
Encapsulation of Water Insoluble Drugs in Mesoporous Silica Nanoparticles using Supercritical Carbon Dioxide, J. Nanomedic Nanotechnol, 2:3.

Regi, M.V., 2012, Mesoporous Silica Nanoparticles:

Their Projection in Nanomedicine, ISRN Materials Science.

Regi, M.V., and Balas, F., 2008, Silica Materials for Medical Applications, The Open Biomedical Engineering Journal, 2: 1-9. 
